\title{
Embedding Education for Sustainable Development through the Well-being of Future Generations (Wales) Act 2015
}

\author{
Dr. Carolyn S. Hayles ${ }^{1}$
}

\begin{abstract}
The Well-being of Future Generations (Wales) Act 2015 is one of a very small number in the World that legislates for Sustainable Development (SD). The Act ensures Wales will make a positive contribution to the achievement of the UN's global Sustainable Development Goals (SDGs), through its seven SDG or Well-being Goals (WbGs). This paper outlines the development, delivery, and feedback from participants on a University-wide stand-alone certificate set up by the University of Wales, Trinity Saint David's sustainability institute, INSPIRE. The primary aim of the certificate is to encourage staff and student engagement with SD issues pertaining to the Act, including opportunities to debate topics on-line. The on-line certificate, which is non-credit bearing, takes participants on a journey through the seven WbGs, giving them an insight into the ambitions of the Goals, supported by research and case studies, which cut across economic, social, cultural and environmental themes. Following the first year of its implementation, the author describes feedback from staff and students taking part in the certificate, including perceived strengths and weaknesses. Going forward, feedback taken on board has improved the certificate for its relaunch during the 2018-19 academic year.
\end{abstract}

Keywords: Sustainable Development, Teaching and Learning, Well-being, Wales, Universities

\section{Introduction}

The course described in this paper is the product of a desire to give all students an opportunity to access learning and teaching on Sustainable Development during their time at the University of Wales, Trinity Saint David (UWTSD). What has resulted is an extra-curricular certificate that anyone associated with the institution can take part in, widening participation from just students to staff, including both academic and nonacademic employees. The on-line, institution-wide, stand-alone, non-credit bearing certificate on 'Sustainable Development and the Well-being of Future Generations', delivered bilingually (through the mediums of the Welsh and English languages), was developed by Dr Carolyn Hayles, Academic Lead for the Institute of Sustainable Practice, Innovation and Resource Effectiveness (INSPIRE), with voluntary support from colleagues from across three of the University's faculties. The certificate was consequently designed for anyone associated with the wider institution; giving them an opportunity to access learning and teaching on Sustainable Development and recognise what the Welsh Government are doing to promote Sustainable Development in Wales.

\footnotetext{
${ }^{1}$ Academic Lead, Institute of Sustainable Practice, Innovation and Resource Effectiveness (INSPIRE), University of Wales, Trinity Saint David, Wales, UK
} 


\section{Sustainable Development and the Well-being of Future Generations}

During the course of the certificate, participants predominantly learn about Wales' Sustainable Development Law, the 'Well-being of Future Generations (Wales) Act 2015'. The Well-being of Future Generations (Wales) Act 2015 defines Sustainable Development in Wales as 'the process of improving the economic, social, environmental and cultural well-being of Wales by taking action, in accordance with the Sustainable Development principle, aimed at achieving the Well-being Goals' (Welsh Government, 2015). The certificate takes participants through each of the Sustainable Development or Well-being Goals and looks at why they were established (with a focus on the spirit of the Act, not legislation); and explores and proposes approaches that may move Wales forward towards achieving these Goals (see Figure 1 and Table 1). It also looks at how the Welsh Goals relate to the UN SDGs (UN, 2018). Participants have an opportunity to consider what the Sustainable Development or Well-being Goals mean for them, their studies/employment, and their future as Welsh citizens. For participants not physically in Wales or not intending to stay in Wales on completion of their studies, the certificate also provides an insight into the UN SDGs.

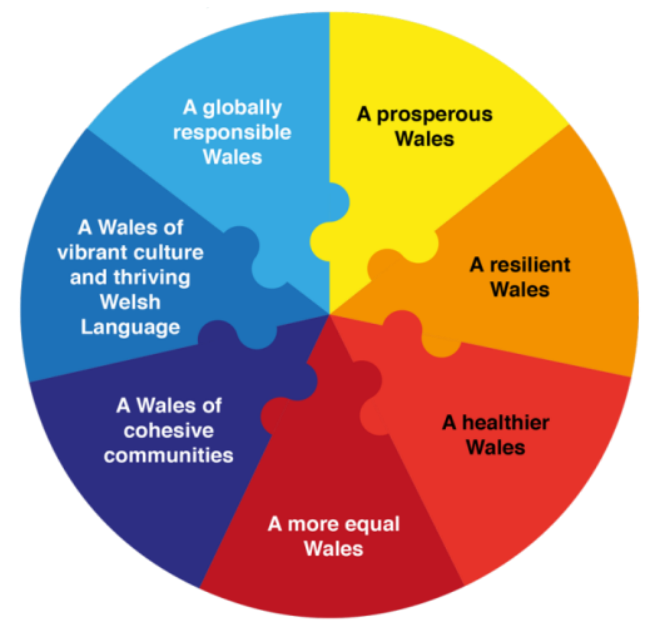

Figure 1: The Seven Sustainable Development or Well-being Goals

Table 1: The Seven Sustainable Development or Well-being Goals (Welsh Government, 2016).

\begin{tabular}{|l|l|}
\hline $\begin{array}{l}\text { Sustainable } \\
\text { Development/ } \\
\text { Well-being Goal }\end{array}$ & Goal Description \\
\hline $\begin{array}{l}\text { A Globally } \\
\text { Responsible Wales }\end{array}$ & $\begin{array}{l}\text { A nation which, when doing anything to improve the economic, social, } \\
\text { environmental and cultural well-being of Wales, takes account of whether doing } \\
\text { such a thing may make a positive contribution to global well-being. }\end{array}$ \\
\hline A Prosperous Wales & $\begin{array}{l}\text { An innovative, productive and low carbon society which recognises the limits of } \\
\text { the global environment and therefore uses resources efficiently and proportionately } \\
\text { (including acting on climate change), and which develops a skilled and well- } \\
\text { educated population in an economy which generates wealth and provides } \\
\text { employment opportunities, allowing people to take advantage of the wealth } \\
\text { generated through securing decent work. }\end{array}$ \\
\hline A Resilient Wales & A nation, which maintains and enhances a biodiverse natural environment with \\
\hline
\end{tabular}




\begin{tabular}{|l|l|}
\hline $\begin{array}{l}\text { Sustainable } \\
\text { Development/ } \\
\text { Well-being Goal }\end{array}$ & Goal Description \\
\hline A Healthier Wales & $\begin{array}{l}\text { A soalthy functioning ecosystems that support social, economic and ecological } \\
\text { resilience and the capacity to adapt to change (for example climate change). } \\
\text { which choices and behaviours that benefit future health are understood. }\end{array}$ \\
\hline A more Equal Wales & $\begin{array}{l}\text { A society that enables people to fulfil their potential no matter what their } \\
\text { background or circumstances (including their socio economic circumstances). }\end{array}$ \\
\hline $\begin{array}{l}\text { A Wales of Cohesive } \\
\text { Communities }\end{array}$ & Attractive, viable, safe and well-connected communities. \\
\hline $\begin{array}{l}\text { A Wales of vibrant } \\
\text { Culture and thriving } \\
\text { Welsh Language }\end{array}$ & $\begin{array}{l}\text { A society that promotes and protects culture, heritage and the Welsh language, and } \\
\text { which encourages people to participate in the arts, sports and recreation. }\end{array}$ \\
\hline
\end{tabular}

\section{Course Development}

The intention was to create as inclusive a learning environment as possible. This is particularly pertinent when considering the subject matter. Tisdell (1995) suggests that a learning environment needs to attend to inclusivity at three levels. A truly inclusive learning environment will therefore:

1. Reflect the diversity of those present in the learning activity through the curriculum and pedagogical style;

2. Attend to the wider and immediate institutional contexts in which the participants work and live; and

3. Try to reflect the changing needs of an increasingly diverse society.

Learners do not live in a vacuum, addressing institutional and societal levels is important, but the most significant level is the selection of appropriate materials and methods that address the characteristics of learning group members (Tisdell, 1995). Addressing the diversity of participants, by selecting appropriate curriculum and course content, was critical in ensuring all aspects of inclusivity were addressed (Shore et al., 1993). This included:

1. Developing an understanding of the groups and sub-groups likely to participate;

2. Representing and respecting the knowledge base of all these groups in the learning and teaching content; and

3. Choosing resources and learning activities that met the needs of all the groups and sub-groups identified.

It was also important to develop a collaborative learning environment, one where participants from different parts of the same institution could come together and attempt to learn something new through shared experience and as equals in a non-threatening, non-hierarchical learning environment (Chiu, 2000).

Seven academics, all volunteers with a passion for sustainability, took part in the development and delivery of the certificate, each taking the lead on one of the seven Sustainable Development or Well-being Goals. As a result, the academics working together were self-selecting, brought together by a shared interest in and appetite for Education for Sustainable Development and Global Citizenship (ESDGC). In addition, a member of the Technology Enhanced Learning Executive, offered invaluable support on the use of on-line learning platforms and tools, supported them. 
The academics pre-recorded each on-line session as two discrete sets of content, one in the Welsh language and the other in English. The University's internal translation service provided support to those academics who do not speak Welsh, and one of the volunteers provided all the Welsh-language voice-overs in these circumstances.

Students access sessions via Moodle, a learning platform designed to provide educators, administrators and learners with a single robust, secure and integrated system to create personalised learning environments (Moodle, 2017), choosing their preferred language. Each of the eight sessions includes a 10-15 minute pre-recorded video on each of the Sustainable Development or Well-being Goals:

1) Introduction;

2) A Globally Responsible Wales;

3) A Prosperous Wales;

4) A Resilient Wales;

5) A Healthier Wales;

6) A more Equal Wales;

7) A Wales of Cohesive Communities; and

8) A Wales of vibrant Culture and thriving Welsh Language.

Presentation of the Goals was enhanced by illustration and animation students from UWTSD's Swansea college of Art, who designed a ten minute video as part of INSPIRE's student internship program (INSPIRE, 2018).

Also included in each session are short quizzes, activities and additional resources. Where possible, all additional resources are available in both Welsh and English, and/or translated into Welsh for participants. Most Welsh Government websites provide Welsh and English content, supporting this dual-language approach to learning and teaching. Each 'session academic' poses a series of questions for certificate participants to discuss online with others taking part in the course; with each discussion moderated by that session academic. These discussions are undertaken bilingually. When considering Wales' journey towards each of the Sustainable Development or Well-being Goals, the Act's 'Five Ways of Working' (long-term, integration, involvement, collaboration, prevention), designed to support sustainable decision-making, are at the forefront of these discussions. This approach provides an opportunity for innovative thinking, reflecting on the way we live our lives and what we expect of our public services. Expected 'Netiquette', referring to rules of etiquette that apply to online communication, are shared with participants to make sure they appear respectful, polite and knowledgeable when posting to the certificate's online discussion forums.

In Session 1, participants are encouraged to take part in the Sulitest. Sulitest.org (2016) is an international initiative assessing core sustainability literacy with a standardised test. Academic institutions and non-academic organisations in more than 50 countries use this tool, which serves as a reference to raise awareness on Sustainable Development and improve sustainability literacy worldwide. The Sulitest requires the participant to answer both international and national questions on sustainability and Sustainable Development. It is an opportunity for the participant to see how much they know and understand about sustainability and Sustainable Development. They can do this through the mediums of Welsh or English, with UWTSD providing the Welsh translation for Sulitest; and are encouraged to revisit the test at the end of the certificate to see whether 
their awareness and knowledge of sustainability and Sustainable Development has changed.

In order to obtain a certificate of participation for the course, participants attempt the quizzes embedded in the eight on-line sessions and contribute to online discussions, moderated by the academic leading the session. They are also encouraged to take part in practical action on campus or in their local community. For some this might mean joining INSPIRE as an intern (INSPIRE, 2018), but for many this means supporting Go-Green Week. Go-Green Week is the People \& Planet's annual national week of action on Climate Change in schools, colleges and universities in the UK. People \& Planet are a student-led movement that empowers young people with the skills, confidence and knowledge they need to make change happen, at home and globally (People and Planet, 2018). Go-Green Week brings together a range of activities to UWTSD campus life for one week in February and includes public debates, film screenings, promotion of environmental campaigns, beach clean-ups and much more.

Finally, although the certificate described above is non-credit bearing, in other words, its completion does not provide credits towards formal education; academic staff are free to use its content to support delivery of teaching and learning around Sustainable Development and the SDGs within the University's degree programs. If Academic staff choose to do this they must develop their own assessment methods; but can do so with the support of INSPIRE if requested.

The certificate on Sustainable Development and the Well-being of Future Generations first ran from October 2017, culminating in Go-Green Week in February 2018, with each of the eight on-line sessions delivered via Moodle fortnightly (with a longer break at Christmas).

\section{Course Delivery}

One hundred and fifty participants signed up for this first run of the certificate. There was a cross section of participants, representing the entire institution, accessing the certificate through both the mediums of the Welsh and English languages. Included within the cohort were undergraduate and postgraduate students including $\mathrm{MA} / \mathrm{MSc}$, $\mathrm{PhD}$ and MBA students, and staff from both academic and non-academic parts of the institution (from facilities staff including cleaners, through to faculty staff including professors). The current cohort of INSPIRE interns were asked to participate as part of their training (INSPIRE, 2018), whilst 50\% of the University's Green Impact teams were required to take part at some point this academic year (the certificate is running again from March -June 2018) in order to obtain the highest (gold) award. Green Impact is a National Union of Students (NUS) scheme that brings together students and staff to green campuses, curriculums and communities (NUS, 2018). Universities can customise some of the requirements, setting their own targets within the framework.

Participants' levels of on-line engagement varied, as would be expected. Some participant were happy to 'receive' the pre-recorded on-line sessions, but reluctant to engage in the on-line discussions, preferring 'action' to demonstrate their engagement with the learning material (e.g. Go-Green Week). Others readily participated in the online discussions, with a small faction proactively creating new discussions. These 
students appear to have benefited the most from the collaborative learning environment created through these on-line forums, with new learning created where participants have actively interacted by sharing experiences and taking on asymmetric roles (Chiu, 2000). Indeed on-line contributions to discussions via Moodle have been both lively and engaging. Participants have been happy to explore the issues proposed, as well as prosing and discussing their own topics as and when they arose. Examples of the breadth of topics covered in the discussion forums are set out in Table 2.

Table 2: Example On-line Discussion Topics from Certificate

\begin{tabular}{|c|c|}
\hline \begin{tabular}{|l} 
Sustainable \\
Development/ \\
Well-being Goal \\
\end{tabular} & Example Discussion Topics \\
\hline $\begin{array}{l}\text { A Globally Responsible } \\
\text { Wales }\end{array}$ & $\begin{array}{l}\text { Do you think the current system of using the international economy to } \\
\text { measure "impact" is a good one? } \\
\text { Do you think we should incorporate additional measures, such as looking at } \\
\text { inequality or quantifying environmental protection, when accounting for } \\
\text { "impact"? }\end{array}$ \\
\hline A Prosperous Wales & $\begin{array}{l}\text { Definitions of a 'prosperous' country relate to fiscal wealth or 'economic well- } \\
\text { being' Does a nation lack economic well-being when food banks seem to be } \\
\text { required? } \\
\text { If there was willingness from banks and perhaps Government to invest in } \\
\text { small start-up companies, with initiatives and not necessarily money, would } \\
\text { that encourage people to take that first step from unemployment to } \\
\text { Employer? }\end{array}$ \\
\hline A Resilient Wales & $\begin{array}{l}\text { How do you think nature and the natural environment can be better used in an } \\
\text { urban setting to promote environmental resilience within our built } \\
\text { environments? } \\
\text { Discuss what you think is the one big environmental issue that needs to be } \\
\text { tackled before any other, and why? }\end{array}$ \\
\hline A Healthier Wales & $\begin{array}{l}\text { Are there any areas of health, which should be prioritised in Wales that you } \\
\text { feel are not currently? } \\
\text { Adverse Childhood Experiences impact upon both mental and physical health. } \\
\text { How can this be prevented? }\end{array}$ \\
\hline A more Equal Wales & $\begin{array}{l}\text { Where would you place yourself on the continuum of sustainability theories? } \\
\text { Does diversity lead to greater well-being? }\end{array}$ \\
\hline $\begin{array}{l}\text { A Wales of Cohesive } \\
\text { Communities }\end{array}$ & $\begin{array}{l}\text { How can we build our social capital in Wales and support our communities to } \\
\text { develop? } \\
\text { When you think about the communities you live/work in, how do you know } \\
\text { that you belong to that community? Are there any that you feel more part of } \\
\text { than others? Why do you think that is? What are the bonds that hold that } \\
\text { community together for you? }\end{array}$ \\
\hline $\begin{array}{l}\text { A Wales of vibrant } \\
\text { Culture and thriving } \\
\text { Welsh Language }\end{array}$ & $\begin{array}{l}\text { Discuss ways to promote the arts, sports and recreation for future generations? } \\
\text { By } 2050 \text { the Welsh Government aim to increase the number of Welsh } \\
\text { speakers to } 1 \text { milion. What steps can you think of that would support Wales to } \\
\text { achieve this aim? }\end{array}$ \\
\hline
\end{tabular}

Previous research has demonstrated the advantages and added benefits achieved from an on-line learning environment, as well as some of the disadvantages experienced (e.g. see Allen and Seaman, 2011, 2013). As an institution with no single 'main' or 'home' campus, it seemed logical to provide a course that everyone associated with the institution could access equally, leaving no participant feeling disadvantaged by geography and work/study schedule. To encourage inclusivity, it was also important that 
the course was delivered via INSPIRE as the University's sustainability institute, and not associated with a specific school or faculty. The flexibility and convenience of on-line delivery in this instance offset any arguments for face-to-face delivery. Indeed, the benefits of delivering the certificate on-line include:

1. Schedule Flexibility: Participants can access the certificate at any time, from anywhere, provided they can $\log$ on;

2. Ease of accessibility: Participants can readily review the sessions, their associated quizzes, resources and discussions. Individuals can also share their thoughts with each other via the on-line discussion forums to facilitate collaborative and inclusive community learning; and

3. Participants control study time: Participants do not have to sit for an extended period to complete the sessions. Pre-recorded sessions are short (10-15 minutes maximum) and can be paused when needed; with the additional resources, discussion etc. read/written as convenient.

Benefits, in addition to the enhanced flexibility and convenience this form of delivery create, include a number of participant enrichment opportunities that resonate with theories of inclusive and collaborative learning:

1. Chance for interaction: On-line courses can be less intimidating than the traditional 'brick-and-mortar' classroom setting, and can help to increase participant interaction. By allowing everyone to have an equal voice, shared ideas grow diverse as well. Participants can also think longer about what they want to say and add their comments when ready. In a traditional classroom, the conversation could have moved past the point where the participant may be willing to comment;

2. Online communications: Academics can be more approachable in an on-line setting. Participants may feel more comfortable debating and discussion issues openly with the session academic (and their fellow participants) through online discussions, rather than face-to-face. Email and on-line correspondence also cuts out having to wait for office hours that may not be convenient for either party; and

3. Time to absorb material: Participants have the 'space' to absorb the material being presented and discussed, supporting their learning.

In addition to the benefits to participants as outlined above, there are cost benefits that include:

1. Little or no financial cost: The certificate is free at the point of use. In addition the on-line learning environment eliminates any costs associated with transportation, childminding, and other expense incurred when attending classes in a more traditional setting; and

2. No requirement to buy (expensive) textbooks: the certificate does not require physical textbooks, as all reading materials are available online or are downloadable free of charge.

Again, these financial benefits ensure the certificate is inclusive and accessible to all.

\section{Course Feedback}

At this stage in the development of the certificate, no formal feedback loops are in place. However, participants were encouraged to take part in a short on-line survey to 
feed back their experiences of taking part in the certificate. Results of the most pertinent questions have been summarised below:

When asked to explain why they decided to complete the WFGA Certificate, participants said:

"I had some spare time and it looked like an interesting area about which I knew very little"

"I wanted to extend my knowledge and understanding of the WFGA goals"

"I decided to complete the WFGA Certificate to better my knowledge before graduating as a primary teacher"

"I wanted to get further insight into the WFGA and have the opportunity to engage with other staff and students on the subject"

"General personal interest in Environmentalism"

"To learn more about sustainable and the WFGA"

"Last year I completed a module about sustainability and the UNSDG's, of which I enjoyed immensely. I took up this certificate as I feel passionately about the goals and planet and Wales"

"I had been a member of the faculty sustainability committee for approximately one year and was interested to explore aspects of sustainability further and gain greater in depth knowledge of the WFGA"

"To learn more about environmental sustainability"

"An interest in sustainability and lack of knowledge regarding its wider impact"

"To develop my understanding of WFGA. To support my teaching and to cascade info4mation to students"

"I'm generally interested in sustainability and equality"

"To give my CV an edge upon graduating with my PGCE. I also believe it would benefit me in my future teaching"

"A good chance to learn more".

One hundred percent of survey participants $(n=14)$, felt that the on-line learning material was 'about right' in terms of its length. Ninety three percent of participants $(n=13)$ thought the academic 'level' of the teaching material was also 'about right'.

When asked what they think is the most important thing they learnt from completing the WFGA Certificate and why, participants said:

"The number of different ways we can improve the well-being of future generations, both environmentally and culturally"

"All the goals have an important part to play if we are to ensure the future well-being of Wales and its people"

"Learnt new information about the 'Deddf Llesiant' [Well-being Law]"

"The level of awareness of environmental issues and what people understand the solutions to be"

"That not enough people are interested in Environmentalism"

"The meaning and how to achieve the objectives"

"The economic element was very useful as this is the area that I was not so well informed in"

"I feel the most important thing I will take from this course is the ways in which to effectively communicate the content further to my own students. I have been keen to 
incorporate sustainability issues into my teaching but have previously struggled to do this effectively"

"How Wales measures up on a global level to environmental sustainability"

"The interrelated nature of each well-being goal"

"The activities with real data on plastics and resource use"

"I found out about many project and research in Wales"

"How important it is to share the message of global citizenship"

"The global issues highlighted by Sulitest".

When asked to describe their experiences of the on-line discussions, participants said:

"It was interesting to read views that were different to my own"

"Interesting and informative as they challenged my thinking and questioning"

"Interesting- being able to consider other peoples comments that I hadn't considered"

"Yes, I found them useful and interesting. It is rare that we have the opportunity to take part in a forum on these matters where people take the time to answer honestly after reflecting on a particular subject"

"Forums everywhere are dependent on the contributions of members, with lower members fewer contributions are made and conversations peter out. It is a natural process. Overall I think that some interesting opinions were discussed"

"Maybe just focus on one question to discuss"

"It was interesting and being able to view others perspectives was useful and informative"

"Yes. It was interesting to see other people's points of view and perspectives on a number of the issues that were being discussed, and also to have the opportunity to present my own opinions without fear of being put down. All discussions were respectful and honest and it was nice to be a part of them"

"I found them quite advanced at times, above what I was really capable of keeping up with given the knowledge I came in with/squired from the course"

"I found the discussions difficult and felt I did not know enough or have a strong enough opinion to be able to engage in actual useful debate"

"I enjoyed this aspect and this was a new venture for me"

"I enjoyed expressing my views"

"Yes, it was very interesting to see and experience other views from people in different sectors with different experiences".

Finally, participants were asked to look back on their time taking part in the WFGA Certificate, and provide a 'thought' that we could share:

"This course shows how the WFGA brings together all aspects of sustainability, and how our actions today can positively affect lives in the future"

"The video clip on the impact of plastic in the oceans on wildlife was incredible and devastating"

"The WFGA Certificate is a big step forward in promoting sustainable development to future generations"

"We do not inherit the earth from our ancestors; we borrow it from our children"

"I feel that taking part in the WFGA Certificate has equipped me with a vast amount of knowledge and has armed me with some ability to community the information further to my own students in my teaching practice. It has been great to engage in academic 
discussion surrounding some of the issues introduced with likeminded people, and also with people who have differing or contrasting opinions to me!"

"A great way to learn how to better impact your country and World!"

"Great introduction to begin engaging with sustainability issues"

"The discussions have reinforced my belief in socio-constructivism as a means to learning, sharing viewpoints and knowledge and different perceptions"

"The WFGA Certificate has interesting content and online discussions and is easy to fit into a busy week"

"An excellent way to share key points with the next generation".

Going forward, the certificate is running unchanged for a second time this academic year (between March and June 2018). The project team meet regularly, and are discussing plans for the 2018-19 academic year certificate, based on the feedback received to date. A workshop, scheduled for May 2018, as part of the University's annual teaching and learning NEXUS conference, will be used to gain further inputs. As heads of School and Module leaders are now requesting that their entire student (and staff) cohorts sign up, numbers are likely to increase in the short term.

\section{Conclusions}

Sustainable Development is about making better decisions using long-term values. It is about thinking about the impacts of today's actions on future generations and learning to live within environmental limits. It is about balancing social, cultural, environmental and economic needs in a way that does not compromise future generations. It is about building capacity now for a more resilient future (Hayles, 2015). The Well-being of Future Generations (Wales) Act 2015 is the first of its kind in the World, where the well-being of future generations is central to Government decision making. The Act ensures Wales will make a positive contribution to the achievement of the UN SDGs, which aim to end extreme poverty, fight inequality and tackle Climate Change, through the introduction of its seven Sustainable Development or Well-being Goals.

The Well-being of Future Generations (Wales) Act 2015 has acted as a catalyst for Welsh Universities to providing learning and teaching around Sustainable Development and the Well-being of Future Generations, which has in turn resulted in the advancement of academics' knowledge, skills and attributes in ESDGC pedagogy. In looking creatively at how to engage both staff and students in the spirit of the Well-being of Future Generations (Wales) Act 2015, INSPIRE at UWTSD has developed an inclusive and collaborative on-line certificate on Sustainable Development, centred around the seven Sustainable Development or Well-being Goals of the Act, with a group of self-selecting academics, passionate about ESDGC. This certificate, accessible to all staff and students associated with the University, has created a platform for discussion and debate around the principles of Sustainable Development. It also promotes practical action through INSPIRE internships and Go-Green Week activities. 


\section{References}

Allen, I. E. and Seaman, J. (2011). Going the Distance Online Education in the United States, 2011. Available online at: www.onlinelearningsurvey.com/reports/goingthedistance.pdf [Accessed 29.01.18].

Allen, I. E. and Seaman, J. (2013). Changing Course: Ten Years of Tracking Online Education in the United States. Available online at: http://www.onlinelearningsurvey.com/reports/changingcourse.pdf [Accessed 29.01.18].

Chiu, M. M. (2000). Group problem solving processes: Social interactions and individual actions. Theory of Social Behavior, 30(1), 27-50; 600-631.

Hayles, C. S. (2015). A Case Study of Capacity Building: Embedding Sustainable Development Principles and Practices at the University of Wales, Trinity Saint David. Proceedings of the 5th International Conference on Building Resilience, Newcastle, New South Wales, July 2015.

INSPIRE (2018). About INSPIRE. Available online at: http://www.uwtsd.ac.uk/inspire/about-inspire/ [Accessed 29.01.18].

Moodle (2017). About Moodle. Available online at: https://docs.moodle.org/34/en/About_Moodle [Accessed 29.01.18].

National Union of Students (2018). Green Impact. Available online at: https://sustainability.nus.org.uk/green-impact/about [Accessed 29.01.18].

People and Planet (2018). Go-Green Week. Available online at: https://peopleandplanet.org/events [Accessed 29.01.18].

Shore, S., Black, A., Simpson, A., and Coombe, M. (1993). Positively different: Guidance for developing inclusive adult literacy, language, and numeracy curricula. Canberra, Australia: Department of Employment, Education, and Training. ED 371112

Sulitest (2016). Building a Sustainable Future Together. Available online at: Sulitest.org [Accessed 29.01.18].

Tisdell, E. (1995). Creating inclusive adult learning environments: Insights from multicultural education and feminist pedagogy. Information Series No. 361. Columbus: ERIC Clearinghouse on Adult, Career, and Vocational Education, Center on Education and Training for Employment, The Ohio State University.

United Nations (2018). Sustainable Development Goals. Available online at: http://www.un.org/sustainabledevelopment/sustainable-development-goals/_____ _Accessed 29.01.18].

Welsh Government (2015). Future Generations Bill. Available online at: http://gov.wales/topics/people-andcommunities/people/future-generations-bill/?lang=en [Accessed 29.01.18].

Welsh Government (2016). Well-being of Future Generations (Wales) Act 2015. Available online at: http://gov.wales/topics/people-and-communities/people/future-generations-act/?lang=en [Accessed 29.01.18]. 